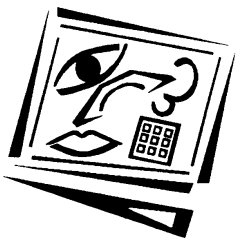

\title{
Domestication of a laptop on a wireless university campus: A case study
}

\author{
Hanna Vuojärvi \\ University of Lapland
}

\author{
Hannakaisa Isomäki \\ University of Jyväskylä
}

Deirdre Hynes

Manchester Metropolitan University

\begin{abstract}
This study reports how university students domesticate their personal laptops at the beginning of studies on a wireless campus. The aim was to examine how students integrate the laptop into their personal education experience, what sort of processes were experienced to render the laptop useful and meaningful, and how gender and IT proficiency influenced this process. Qualitative interview data with twenty students (identified and selected by quantitative survey) was analysed using the grounded theory approach during which a multi-aspect domestication process was identified. Results highlight the importance of a structured way of organising laptop initiatives in universities. It is important that students have the kind of support available that best suits their needs. Pedagogically, successful domestication enables students to integrate the computer into their learning experience. However, we argue that successful domestication allows the artefact to become more than just a tool for learning, but also an integral part of an individual's existing media environment. In effect, comfort of use and IT capability is regarded as only one way of expressing successful domestication. This article adds to the growing number of studies using domestication as an analytical and theoretical framework and considers the phenomenon in an under-researched area.
\end{abstract}

\section{Introduction}

In recent years, educational organisations have been taking courageous steps in the ways they aim to apply information and communication technologies (ICTs) in teaching and learning processes. One example of such an initiative is that taken at the University of Lapland, Finland, where all entering students since autumn 2004 have been given an opportunity to acquire a laptop through the university. In practice, this means that a student pays one-third of the cost of the laptop and the university covers the remainder. Additionally, a wireless local area network (WLAN) has been launched on campus. The original idea to take such an initiative was purely administrative and it has aimed among other things to give students an opportunity to organise studies flexibly regarding schedules and physical places, and to decrease maintenance costs for computer classes (Vuojärvi, Lehtonen \& Ruokamo, 2008; Räisänen, Lehtonen, Ruokamo \& Isomäki, 2005.) 
Along with these administrative and economic implications, such an initiative can have a deeper impact on the pedagogical practices. Mobility afforded by wireless laptops makes it possible to study flexibly regarding times and places (Eriksson, Vuojärvi \& Ruokamo, 2009). It provides a convenient way for students to store and carry their own study histories and facilitates collaboration with other students. Many keys to pedagogically successful use of ICTs have been identified in previous research, which has also yielded practical recommendations. The most mentioned include longterm strategic pedagogical planning of implementing technology in education (Jonassen, Lee, Yang \& Laffey, 2005; Nicol \& McLeod, 2005); high quality of faculty utilisation of the technology for teaching and students having choices as regards technology (Demb, Erickson \& Hawkins-Wilding, 2004); engagement of students in active learning and problem solving through ICTs (Barak, Lipson \& Lerman, 2006); and support for the development of network based communities and feelings of trust (McInnerney \& Roberts, 2004).

The concepts of ambient intelligence and ubiquitous computing foresee a future where technologies embed themselves and disappear into the fabric of everyday life (Punie, 2003). This shift brings about the possibility of laptops fulfilling increased everyday functions and increasing their value and worth to the user. The emphasis is on user friendliness, user empowerment and support for human interactions encompassing a number of dimensions: technical, economical and social. Although campus-wide technology programs utilising laptop computers have been executed worldwide, research papers discussing how students experience the process in an educational setting are practically absent. What remains unclear are the mechanisms through which students become familiar with their laptops, and start using them in learning as well as in everyday life settings.

This article reports a study which sought to find out how university students put their laptops into use and domesticated them before entering teaching and learning processes utilising the laptops on a wireless campus. This case study investigates how the domestication process is manifested and what students do during that process. We were also interested in the gender dimension and differences between ICT novices and ICT experienced students in their actions. We use the term 'ICT experienced' here to describe a student who has versatile ICT skills and can apply those skills creatively. We did not want to use the traditional concept of 'expert' that is usually coupled with the concept of 'novice', because expertise is its own acknowledged research area, and this research does not aim to contribute towards expertise research.

The data for this study of students' domestication of laptop computers were collected by qualitative interviews with twenty students who were selected as interviewees through explorative sampling. The article is structured in the following manner: firstly the topic is delineated through a theoretical background presenting the idea of technology domestication, and the related research questions are presented. Secondly, data collection and grounded theory analysis procedures are described, and finally, results are presented and discussed.

\section{Domestication explained}

Jones, Dirkinck-Holmfeld and Lindström (2006) emphasise that in education, ICT adoption should be considered in relation to their later use in learning. According to Cretchley (2006), computer confidence has an impact on how motivated students are to learn in an ICT-enhanced learning environment. Since confidence is usually gained 
through successful use and problem solving, students should have positive experiences of using their laptops right from the start. Still, it remains unclear as to what exactly happens before students participate in courses on a wireless campus where mobile technologies such as laptops are exploited, and before they use their laptops in everyday life. How do students get acquainted with their new tool? Before learning with technology, students need to learn how to use technological tools. The term 'tool' here is appropriate, as laptops bought for educational purposes are usually conceptualised as educational tools and mindtools (Lehtonen, Ruokamo \& Tella, 2004) which refer to mobile tools that support thought and activity and are well suited to a particular situation and activity - in this case laptop computers. However, we are sensitively aware that computers can achieve deeper meanings which go beyond mere functional attributes as they progress through their lifecycle, in other words, as they become domesticated.

In this case study, the phase that takes place before entering courses on a wireless campus is explored by applying the concept of domestication (Hynes, 2003, 2005; Silverstone, Morley, Dahlberg \& Livingstone, 1989; Silverstone \& Hirsch, 1994). Domestication is a concept widely used by researchers to explain how technologies and in particular, media and computing technologies become part of our everyday life. As Silverstone explains "by domestication I mean something quite akin to the domestication of the wild animal... a process of taming or bringing under control. Technologies, television and television programmes must be domesticated if they are to find a space or place for themselves in the home" (Silverstone, 1994: 83). It is used to help explain patterns of ICT usage and non-usage; and adoption and experience (see Haddon, 2006, for a valuable overview of the concept and related studies). Domestication has typically been associated with media technologies and the household. The original formulation of the concept was developed by Silverstone and researchers (1989) in the CRICT project in 1989. Further development of the concept continued both in the UK and in Scandinavia. In the UK, Silverstone, with Hirsch, collaborated to co-edit a book on technologies in domestic spaces, while in Norway, Lie and Sørensen (1996) edited a collection of papers with the focus of making technology our own.

The domestication of technology approach has been applied not only to household media technologies (such as televisions and radio) but also to smart homes, cars, and working environments (Pierson, 2006). The domestication approach moves beyond linear adoption models (Rogers' S-curve (1995), for instance) and allows for a more embracing analytical methodology taking in a wider range of variables and contexts. The value of the domestication approach in contrast to more technologically focused or technologically deterministic adoption models is that the user and the social conditions and environment of use is privileged (see Hynes \& Richardson, 2009), While Habib (2005) attempts to apply domestication to learning environments, it is noticeable that any consideration of domestication of technologies within educational settings is lacking. It is within this context that we use domestication to help us understand how educational technologies become part of students' everyday life.

The concept of domestication catches the practical, temporal and spatial place, but most importantly, it underlines how this is mixed with the cultural as an expression of lifestyles and values. Silverstone et al. (1989) describe four aspects, or non-discrete elements, identified to analyse this process of how technologies become part of everyday life: 1) appropriation, 2) objectification, 3) incorporation, and 4) conversion. In the appropriation phase, possession and ownership are central. The acquisition of the 
technology is the main activity or concern. A technology gets appropriated as it is sold, and then owned or possessed by an individual or household. That is the point at which a commodity crosses the threshold between public and private, beginning its new life as a domestic or owned object. Objectification tries to capture how values, tastes or styles are expressed through the display of the new technology. It involves both a spatial aspect (where it is placed in the house), and a temporal aspect (how it is fitted in the time structure of the daily routines and habits of the owner). However, the spatial aspect is more central in this phase. The incorporation phase emphasises how ICTs are used, and the temporal aspect is more central in the incorporation phase. Silverstone and Hirsch (1994) suggest that for an artefact to be incorporated it has to be actively used, such as in the performance of a task. The conversion phase is concerned with the relations between the households or individuals' internal/personal affairs and the public domain or outside world.

Domestication is not a fixed or linear process (Hynes, 2009). We have described the four phases above in a fractured sense, but in reality, individuals can experience aspects of domestication without necessarily doing so in the order explained above. Silverstone et al. (1989) have separated the phases in order make sense of the processes experienced by individuals and households. In this sense, domestication, both as a metaphor (i.e., the taming of wild animals can be used to described the process of how individual's react to and tame new, wild and strange technologies), and as an analytical concept, is used to find the crossover where technologies and people adjust to each other and find (or do not find) a way to co-exist. Central to the domestication process is the attempt to make technologies fit into their surroundings in a way that makes them invisible or taken for granted. Domestication is about giving technology a place in everyday life. It is important to notice that even though we, in this paper, consider domestication in a study related setting where the main goal of domestication is to put it into use in studying and learning, the technology at hand adjusts itself to students' lives in a more profound way.

Hynes and Rommes (2005) have used the concept of domestication to argue that policy makers, course designers, and educators need to pay attention not only to material resources (such as hardware provision and tuition), but also to the symbolic resources students bring with them (such as motivations, reasons to learn and attend, and the importance and meaning the artefact holds for the individual). By addressing both material and symbolic resources, the likelihood of successful domestication is enhanced.

There are some aspects that make the situation at the University of Lapland special. In this case study, the focus is on students who put their laptops into operation in learning processes for the first time. There were not any organisationally established and structured practices that the students could have followed during their domestication process. We are particularly interested in the early phases of domestication - specifically, how the students assigned early meanings, how they engaged with the artefact individually and in groups, and how they set about making the technology their own. The university arranged some introductory sessions on the use of laptops, but the students did not find them at all useful. Recent research (Osika \& Sharp, 2003) has, however, identified that students should have some knowledge of how to use computer operations and utilities, to manage files, and the skills to use some basic office software. We would also highlight the importance of having knowledge of features related to the aspect of mobility afforded by laptops and WLAN that might bring about the additional need for new skills. Mobility and mobile learning 
implies the possibility of learning in various locations at various times with the help of mobile tools - in this case, laptop computers. Technology has an important role in learning processes as a mediator of thoughts, interactions, and activity. (Ruokamo \& Tella, 2005.)

The main research question of this case study was formulated as follows: How do university students domesticate laptop computers at the beginning of their studies on a wireless campus? This question can be expressed in terms of two sub-questions:

a. What kinds of actions do students take when domesticating laptops, and are there differences between female and male students, or ICT novices and ICT experienced students in this?

b. How is the domestication process manifested in this case study?

\section{Data collection and analysis methods}

Participants were selected through exploratory sampling performed in order to find a representative subsection (Gilbert, 1993) of ICT experienced students and ICT novice students in the student population. Sampling started by sending a questionnaire to all 682 students who entered the university in the autumn of 2004, before the laptops and WLAN were adopted for their use. In the questionnaire, students were asked for background information and queried about their previous experiences and expectations regarding the use of computers and networks and how they reconciled the demands of studying and family life. Married students and students with children were asked about their housing arrangements and their family situation as well as about their expectations regarding the demands of studying and family life. (Räisänen et al., 2005). Most of the questions were Likert scaled items on a scale from 1 to 5, but also open ended questions were included as well as a SWOT (strengths, weaknesses, opportunities, threats) analysis of using laptops and networks in learning. With the questionnaire was also sent a letter, in which the research topic was introduced, and in which students were also asked for their informed consent (cf. Sieber, 1992). A total of 197 students returned questionnaires, which is $29 \%$ of the whole population.

Next, a K-means cluster analysis of the statistical data was performed on the basis of the answers students gave to 18 five-point Likert scaled questions (end points from "Not at all" to "A lot") concerning their own perceptions of their skills and previous experiences in using computers, different kinds of hardware and software, as well as networks and network services. In the K-means cluster analysis method, the amount of final clusters is decided beforehand (Aldenderfer \& Blashfield, 1987), and the goal was to divide the students into two groups of ICT experienced students and ICT novice students. After performing the K-means cluster analysis the goal was to find ICT experienced students and ICT novice students in the groups of female and male students. Thus, the two clusters were cross-tabulated with a question about the respondents' gender. The results of the K-means cluster analysis and the crosstabulation are presented in Table 1 below.

On the basis of the cluster analysis, students distributed quite evenly into a group of ICT experienced students who are marked with number one in Table 1, and ICT novice students, who are marked with number two. Out of the total number of respondents, $47 \%(\mathrm{n}=84)$ of the students were ICT experienced students, and $53 \%(\mathrm{n}=96)$ were ICT novice students. The difference between ICT experienced students and ICT novice students was statistically significant in all variables that were included in the cluster analysis at a $p$-value $<0.05$. Cross-tabulation shows that $45 \%(n=63)$ of women are ICT 
experienced students, and 55\% $(\mathrm{n}=78)$ of women are ICT novice students. Out of the group of men, $54 \%(\mathrm{n}=21)$ are ICT experienced students and $46 \%(\mathrm{n}=18)$ are ICT novice students.

Table 1: Clusters of ICT experienced and novice students, and gender distribution in the clusters

\begin{tabular}{|l|l|c|c|c|c|c|c|}
\hline \multicolumn{2}{l|}{} & \multicolumn{2}{c|}{ Male } & \multicolumn{2}{c|}{ Female } & \multicolumn{2}{c|}{ Total } \\
\cline { 3 - 8 } \multicolumn{2}{l|}{$\begin{array}{l}\text { Cluster number } \\
\text { of cases }\end{array}$} & No. & $\%$ & No. & $\%$ & No. & $\%$ \\
\hline Total & 1. ICT experienced students & 21 & $54 \%$ & 63 & $45 \%$ & 84 & $47 \%$ \\
\cline { 2 - 8 } & 2. ICT novice students & 18 & $46 \%$ & 78 & $55 \%$ & 96 & $53 \%$ \\
\hline
\end{tabular}

After cross-tabulation, twenty students were randomly chosen as interviewees on the basis of the previous analysis. Ten from each cluster, and an equal number of male and female students representing all faculties of the university were chosen. These students were contacted by phone and asked for their consent to be interviewed. All the students were already familiar with the research topic, since they had responded to the questionnaire sent to them in the autumn of 2004, but the main points of the research were still reiterated. If they did not want to participate, another student representing the same cluster was selected and contacted. If they were willing to take part, an appointment was scheduled. The interviewees comprised of twenty first year Finnish university students between the ages of 21 and 53 years. There were 10 female and 10 male students. All five faculties in the University of Lapland were represented, as in this group of twenty students, there were three Arts and Design majors, two Social Science majors, six Education majors, four Business and Tourism majors and five Law majors.

Interviews took place during the summer and autumn of 2005 . By the time of the interviews students had been using their laptops for one year after receiving them in September and October 2004. Interviews were conducted by using a qualitative interviewing method (Kvale, 1996; Clemmensen, 2004). Interviews took place at the university in a negotiation room or an office. Before the actual interview questions, the interviewees were asked if it would suit them if the interviewer was to tape the interview and write notes on a laptop computer. Also, the issues of maintaining confidentiality and interviewees' anonymity were discussed. Every interview included the following themes: 1) experiences of taking the laptop and wireless network into use, 2) data security and usability issues, and 3) issues related to studying and learning. According to the chosen interview method (Kvale, 1996), the interviewer wrote notes during the interview on a laptop and presented her own interpretations to the interviewee as the discussion forwarded. The interviewee corrected the researcher's interpretations if needed. One interviewee sent an email to the interviewer after the meeting and added some things that he had forgotten to say during his interview. These points were added to the transcription of the interview.

The analysis of the interview data was carried out using the grounded theory approach (Glaser \& Strauss, 1967; Corbin, 1997; Strauss \& Corbin, 1998; Suddaby, 2006) with the aid of the AtlasTi qualitative analysis software. Grounded theory process consists of three steps of coding. These steps are: a) open coding, b) axial coding, and c) selective coding. It is typical for grounded theory research that data collection, analysis, and interpretation are interwoven. The data does not have to be collected in its entirety before the analysis, but the coding can start as soon as some data is collected. New data is constantly compared to existing codes and categories. 
The reliability of the interviews was strengthened through the discussions. The chosen qualitative interviewing method (Kvale, 1996) included discussing the researcher's interpretations of the interviewees' answers; interviewees had the possibility to correct and fill in the interpretations, even though the selected interviewing method was not carried out as it was originally decided, but the interpretation phase was gone through during the interviews. The questions were designed to be simple and understandable so that the risk of misperceptions on the part of interviewee would be minimised (Cohen, Manion \& Morrison, 2007). The analysis process carried out in this study and the resulting categories are presented in the following section.

\section{Results and discussion}

The three phases of the grounded theory analysis and resulting categories are presented below in Figure 1. The analysis is described in detail in the sections that follow. There are also quotations from the interviews; students' names are changed to protect their anonymity.

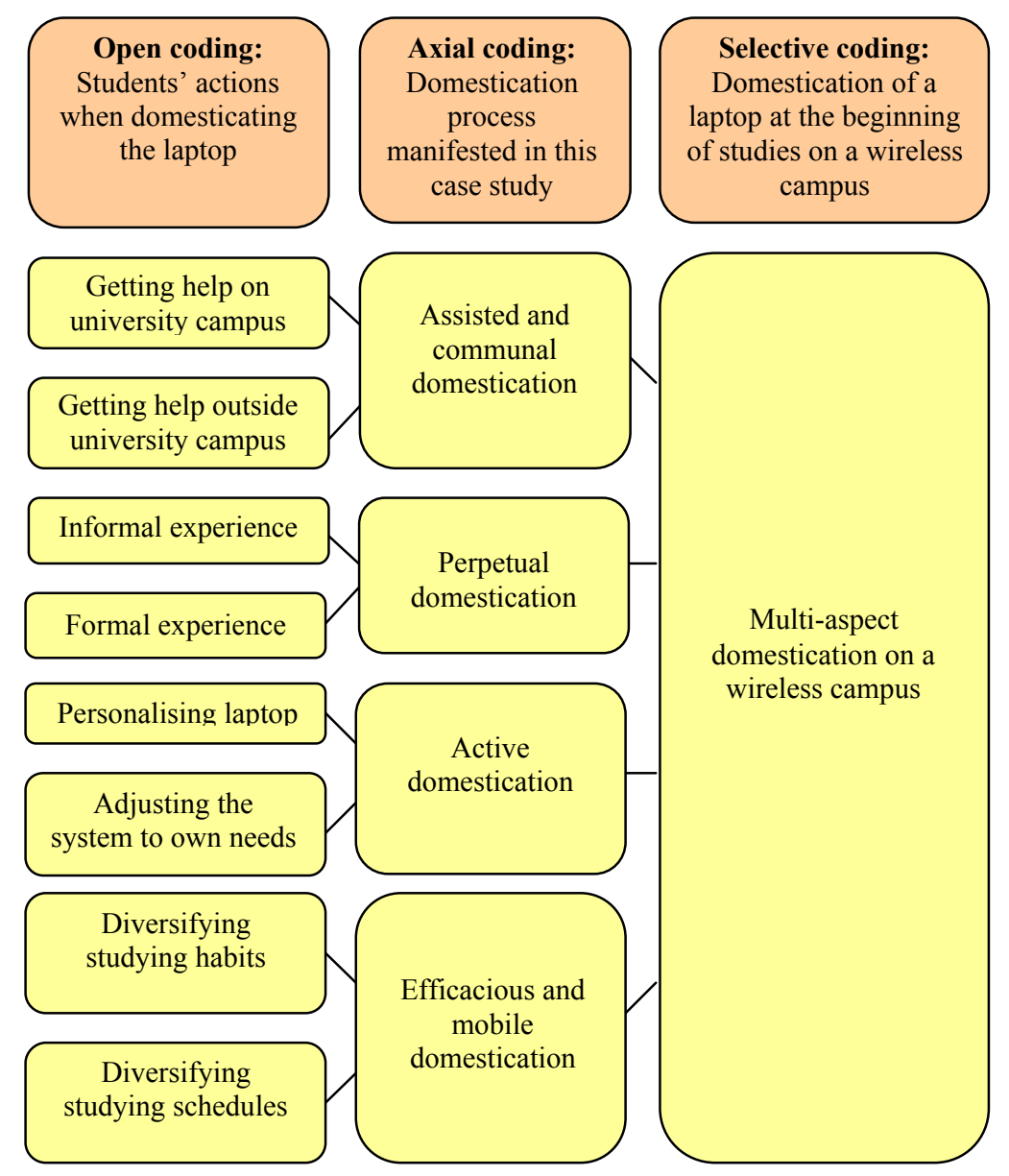

Figure 1: Phases of grounded theory and the resulting categories 


\section{Open coding: Students' actions during the domestication process}

The first step, open coding, started simultaneously with the interviews by reading through the transcribed interviews and identifying and naming concepts relevant to the focus of the study, that is, how university students domesticate laptops at the beginning of their studies on a wireless campus, students' actions during the domestication process, possible differences between female and male students, and between ICT novices and ICT experienced students, and also domestication process' manifestation in this case study. We initially found seventeen concepts which were placed in eight categories: a) getting help on the university campus, b) getting help outside the university campus, c) informal experience, d) formal experience, e) personalising, f) adjusting the system to their own needs, g) diversifying studying habits, and h) diversifying studying schedules.

The first category - getting help on the university campus - was created from two concepts: help from peer students and help from university personnel. It was these two concepts students used when describing how they had help in the domestication process when they were present on the university campus. As the students of the class of 2004 were the first who had the opportunity to acquire laptops, there were not any older students who could have been of assistance in this matter. Hence, they had to deliberate about laptop problems with their peer students. Some of the students also had help from staff members, mainly from the help desk at the university's ICT services. Also, some training lectures were organised at the University by the laptop deliverer, but students did not find these lectures helpful. They said that they would have needed deeper knowledge about the functions of the laptop and of the WLAN. They also thought that it would have been more beneficial if the training was organised by university personnel, since they have detailed information about the campus and the university's information systems.
After we got the laptops I participated in the training session, but I didn't find it useful. Mainly we were instructed on how the keyboard works and what components the laptop comprises of, what's inside of it, how one can load the battery and what kinds of ports there are. [...] I would have needed more instructions concerning data security issues. Now we were just told that we should update the virus protection software, but the practical 'where', 'when' and 'from who' were left unanswered. Also issues regarding WLAN installation and use were missed. (Jonathan, ICT experienced)

The second category - getting help outside the university - was created from two concepts: help from a family member and help from a friend. Help gained outside the university campus had a significant influence on how the domestication process succeeded, especially for female students.
Taking the laptop into use has been easy, all the software I needed was already installed. I live with my boyfriend, who works in the IT field and he has given me a lot of support, so it wasn't scary to turn the laptop on for the first time. I think that taking the laptop into use probably wouldn't have been difficult, but the help made it easier anyway. (Katie, ICT experienced)

The third category - informal experience - was created from two concepts: previous own computer and previous computer in the family. Students used these two concepts to describe what kinds of previous experiences they relied on during domestication. Some of them had their own computer before, and some had used their parents' computers. Dividing previous experiences into these two concepts was relevant, because the students identified the responsibility that came through actually owning a 
laptop. When one uses a computer that is not in their possession, responsibility is not perceived to be as great as if it were one's own. The fourth category - formal experience - was created from two concepts: ICT studies and ICT work. This category was created to describe past experience students had gained through ICT studies or ICT work. This category differs from the third category in that the skills acquired through formal experience were gained trough training that was designed according to some educational standards, or to match the demands of working life.

Putting the laptop into use has been easy. I work as a PC advisor, so that has undoubtedly affected the easiness. (Sarah, ICT experienced)

The fifth category - personalising the laptop - was created from two concepts: editing exterior features and making their own laptop unique. It seems that students appreciated the fact that the laptops were their personal tools, and they did not have to share them with anyone. This, of course, enables personalising the laptop to their taste by, for example, changing the wallpaper on their desktop, or changing or even creating their own screen savers. Also, organising the directory was one important way to make the laptop more personal, and make it feel as if it was one's own.

The sixth category - adjusting the system to one's own needs - was created from three concepts: installing hardware, installing software, and installing Internet access (WLAN and/or other). This category is more about what kinds of tools the students assumed they would need during their studies. Most mentioned additional hardware installed being mice and scanners. One significant type of software that students wanted to adjust to their own needs seemed to be data security software. There was a firewall and virus protection already installed, up and running on the laptop, but many students said that they wanted to adjust their protocols to suit their own working habits, and some of them also changed the software to something that they perceived as better. Changing the software seemed to be a common strategy also regarding other types of software than just that of data security. Regardless of the fact that there were some office tools already installed, many students wanted to have software that was more familiar to them, and did not want to learn how to use unfamiliar software. Students said that it was important for them to find, for example, word processors, presentation graphics, spreadsheets, and Internet browsers that would support their individual studies the best way possible. They could then complete their assignments using only one computer, and did not have to use the computers in lecture rooms and then carry files back home on, for example, a memory stick or a disk.

It is a joy and also very handy to take my laptop with me as I go home and continue working there. (Jack, ICT experienced)

I uninstalled the Star Office software totally and installed the Microsoft Office instead. It is easier for me to use than this software that was on the laptop. (Joey, ICT experienced)

The seventh category - diversifying studying habits - was created from two concepts: altering previous studying strategies, and trying out new studying strategies. This category has to do with the choices students make when deciding how they want to use their laptops in studying and learning. For example, using the wireless local area network is not a certainty for every student. Beside the fact that some students had had difficulties when installing the WLAN, the reasons whether or not to use the WLAN had more to do with their own actions. 
I haven't used the wireless LAN at all. That is a totally conscious choice, because I think it's more than likely that I'd surf the Internet during lectures if I had the network installed. (Jonathan, ICT experienced)

The eighth and final category - diversifying studying schedules - was created from two concepts: studying in versatile environments, and studying at versatile times of the day. These two concepts describe the way students started to try out scheduling their daily life in a new way. Having a mobile laptop in their use enabled participation, even from a distance. It was very evident from the participants' narratives that the idea of wireless access and mobile access was an attractive option and an appealing feature of computer use within the university. Students spoke about their own individual experiences, and how it had made a difference to their lives, and how it had proven to be a useful tool when it came to studying outside the university.

If we had only one computer in use at home, it would be in somebody's bedroom and when I had the time to study, that somebody would be sleeping in that room. Now I can go someplace else. Also when thinking about motivation it's good to be able to do things when I feel like it and wherever it's most peaceful. (Sarah, ICT experienced)

The first sub-question of this case study was: What kinds of actions do students take when domesticating laptops, and are there differences between female and male students or between ICT novices and ICT experienced students in this? The analysis revealed that the students use a great amount of time in adjusting the laptop to their own individual needs and their studies. This confirms the view presented by Jones and his colleagues (2006), according to which, technology adoption should be dissected in the light of the context in which it will be used. The domestication process is affected by the purpose for which, and the context in which the laptops are used. Social support is a critical feature that is used to assist the process; this was important especially to female students. Students reported that they had solved problems in collaboration with each other, which accentuates the social aspects of the domestication process. These social aspects could be considered and supported as a part of a forming stage suggested by McInnerney and Roberts (2004) that precedes network based learning. Students would have more opportunities to collaborate with each other during the early stages of domestication, in addition to getting to know each other.

Personalising the laptop is also important during domestication. This reminds us that students who invest in personal learning tools are, in a way, also consumers who want to have choices (Demb et al., 2004). In large initiatives such as this, it is practically impossible to provide, for example, a wide choice of laptop brands and types, software or hardware in order to maintain technical support for the laptops. In this case, students have administrator user rights to their own laptops, and therefore have a choice of, for example, software and hardware. According to our results, previous experiences are also important and are put to use when domesticating the laptop. As students become familiar with their tool, they start to diversify their studying habits as well as schedules, as the laptop affords mobility for them. Osika and Sharp (2003) reported the ability to use computer operations and utilities, to manage files, the skills to use word processors, presentation graphics, spreadsheets, databases and Internet browsers as the minimum technical competencies that students should have before entering network based education. Our analysis of domestication on a wireless campus revealed that in addition to these factors, students also perceive data security skills and Internet connection (WLAN or other) installation and maintenance skills as critical prerequisites for entering network based courses. 
In addition to finding out what students actually do during the domestication process, it was also interesting to see whether there would be differences between female and male students, and also between ICT novices and ICT experienced students. According to our analysis, it seems that male students preferred to put the laptop into use single handed, with only a little bit of help from their friends, if at all. They also relied on the help provided by the university's organisational support services, and expected more that the training organised by the university would answer their questions. None of the men mentioned having help from family members. Women instead relied heavily on their social support networks, and had a lot of help from family members and friends, regardless of what their skill level was. Help was sought if there were concrete problems with the laptop computer, but social support was also used as a backup, just in case problems appeared.

ICT novice students did not have a similar opportunity to gain from previous experiences of using computers and networks at home, school or work, as ICT experienced students had, which is as expected. This is why the domestication process seems to have gone more smoothly for the ICT experienced students. When looking at the level of the skills of these two groups, it has to be noted that being an ICT novice student does not mean having no experience with using computers and networks. Only one novice interviewee said that she had been avoiding computers until now, but everyone else had had some experience with using computers. The differences between these two groups can be seen in the versatility of the actions students took during the first stages of the domestication process. ICT experienced students seemed to be more confident about what they would need in their studies and other areas of life already at the beginning, and thus, for example, installed more software and were braver in tuning their laptops more to meet their personal tastes. ICT novices seemed to be content with less, and started their studies with the basic tools only, and added features and software to their laptops as time went by.

\section{Axial coding: The domestication process manifested in this case study}

The second step of analysis, axial coding, means categorisation of related phenomena. We started to look for relations between individual concepts and form categories that were again labelled. During this process it was noticed that at the early stages of taking the laptop computer and WLAN into use, social support seemed to be an asset. Help was mostly needed when new software had to be installed and learned, or when the laptop had to be connected to the WLAN. The two categories that describe the social support are 'Getting help on the university campus' and 'Getting help outside the university campus'. The new category, formed on the basis of these two open coding categories, was labelled 'Assisted and communal domestication'.

As technologies progress through their life cycle, domestication can be interrupted, slowed, accelerated, or even stopped. We see that some students spoke of their past experiences and how that influenced their domestication process. These concepts can be found in the open coding categories 'informal experience' and 'formal experience'. These categories were reassembled to the axial coding category of 'perpetual domestication'.

The third axial coding category, 'active domestication', was formed on the basis of two open coding categories: 'personalising laptop' and 'adjusting the system to one's own needs'. Active domestication resembles objectification that was present in the 
domestication process proposed by Silverstone et al. (1989). As the students move through the phases of getting to know their laptop computers, and overcoming the many teething problems, they begin to become more active in the process by assigning functions and meanings to the technological artefact. This is achieved by personalising the interface and adjusting the system to the needs that studies present to the use of the laptop.

The fourth and final axial coding category, 'efficacious and mobile domestication', was formed on the basis of two open coding categories: 'diversifying studying habits' and 'diversifying studying schedules'. This resembles the incorporation aspect presented earlier (Silverstone et al., 1989). Efficacious or successful domestication comes about when the technology is successfully embedded within the daily routine and habits. The participants spoke of their success in adapting the technology to fit their lives and their multiple purposes.

The second sub-question of this case study was: How is the domestication process manifested in this case study? The grounded theory analysis revealed the four aspects of the domestication process on a wireless campus. The first aspect is the assisted and communal domestication, which highlights the importance of social support during domestication. What seems to be characteristic to domestication taking place in a university setting is the help provided by families, friends, and peer students to those who need assistance at the early stages of domestication. Even for the ICT experienced, the knowledge that social support is available when needed can smooth the early stages of the process. Stewart (2002) uses the term local expert to describe the types of help such experts provide. He states that individuals provide trusted, if not always reliable, help for others making their steps in forming attitudes to innovations and adopting them. The local expert also provides on going support which is local and relative. Related to the notion of assisted domestication referred to above, it is also possible to identify a kind of communal domestication between friends and students, who found themselves in the same situation with regard to their own personal domestication of the laptop. We can see parallel domestication occurring between students who are in roughly the same stages of domestication.

We have used peer support. [...] I don't think that we would have collaborated as much as we have if we didn't have laptops. (Jack, ICT experienced)

The second aspect of the domestication process manifested in this case study is perpetual domestication, which describes how earlier experiences are used to assist the domestication process. Having previous skills and experiences has a positive influence on the fluency of taking the laptop into use and taking part in the community's activities. For example, if the operating system is already familiar, it is easier to get started even if the hardware is not so familiar.

I have some experience in using laptop computers, which made things a little bit easier. I got my new laptop switched on and acted according to my previous experiences, so I succeeded. (Helen, ICT novice)

The third aspect is active domestication, in which students make their laptops look like their own. The fourth and final aspect is efficacious and mobile domestication, which describes the various situations and times students started to use their laptops in. 
I have tailored my computer to look more like me, for example, by creating icons of software and files that are important for me, installing a screen saver and desktop wallpaper. I have also organised folders and files so that they are easy for me to find. (Joanna, ICT novice)

I can write for example in a bus, a hallway or when I'm waiting for something. At home, I don't have to share the computer with my wife and interrupt my task if she needs to use the computer. Currently I'm writing my masters thesis and I'm not dependent on the place I'm in, but I can take my books and laptop and go, for example, to a pier to write. [...] I don't have to ask for quietness from anyone, but go to a quieter place myself. (Mark, ICT novice)

The domestication process revealed in this case study has some differences when compared to the domestication process described by Silverstone et al. (1989). During analysis, we encountered a scenario of forced domestication, or artificial domestication. This is because some of the work (end)-users and consumers traditionally have to do to bring about domestication is skipped over, or artificially supplied as the laptop, here the technological artefact, as it is already provided for by the university. This is particularly evident in the early stages of domestication where appropriation involves the social processes of obtaining the artefact and the kind of work that involves. This removes the processes of justification, purchase, research, choice and decision of the model. These early phases of domestication are crucial in the meaning generation process.

\section{Selective coding: Domestication of a laptop on a wireless campus}

Finally in the third step of the analysis, selective coding, the aim was to integrate categories created during the axial coding. This seems similar to the integration done when moving from open to axial coding, and actually it is, but the integration in the last phase of the analysis is done on a more abstract level. The central category for all the categories found during the previous steps, was created and labelled 'Multi-aspect domestication on a wireless campus'.

The main research question of this case study was: How do university students domesticate laptop computers at the beginning of their studies on a wireless campus? Grounded theory analysis of interview data revealed a multi-aspect domestication process consisting of: (a) assisted and communal domestication, (b) active domestication, (c) perpetual domestication, and (d) efficacious and mobile domestication. According to this study, students approached the domestication process from four aspects. The perceived value of each aspect for an individual student depends greatly on students' personal experience and needs. For example the need for social support is not so critical for everyone, some students approach the process on their own and some need closer guidance at the beginning. Further, for some students the laptop is only a tool for learning and they do not use it for any other purposes, but for others it is also a tool for making a living and more integral part of their everyday lives used for entertainment and running errands.

It is worth stating that even though we have introduced and analysed domestication from multiple aspects, in reality, the experience of domestication is never as simple as four easily managed and identifiable aspects. While it is useful for academic papers such as this one to explain the process in sections, the experience of domestication is ultimately a more fluid process with overlapping aspects, blurred boundaries, and is one which is unfixed in sequence and nature. Also, even though we present the 
domestication process here as something that takes place at the beginning of the studies, it is a reality that the domestication and studies start somewhat at the same time, and students probably use their laptops already, even though they are still in the middle of the process. The amount and type of support students need changes as the time passes, the ways in which laptop is utilised become more diversified and in time, the tools start to look like their own for their users.

\section{Conclusions}

The aim of the study presented in this article was to find out how university students put their laptops into use and domesticated them before entering teaching and learning processes utilising the laptops on a wireless campus. This case study investigated how the domestication process is manifested and what students did during that process. We were also interested in the gender dimension, and differences between ICT novices and ICT experienced students in their actions. The data were collected by qualitative interviews with twenty students who were selected as interviewees through explorative sampling, and analysed by using grounded theory approach.

The analysis revealed a multi-aspect domestication process taking place at the beginning of studies on a wireless campus. Our findings suggest that in universities where similar laptop and wireless campus initiatives are taking place, a common 'one size fits all' approach to student engagement in ICT provision should be rejected. This can be seen as being beneficial to both teachers and students. Learning processes that involve students applying theoretical concepts to hands on practice with the help of ICTs, such as described by Barak et al. (2006), require students being familiar and confident with their tools. This enables both students and teachers to concentrate on the subject, instead of the technical aspects. Students call for broader training organised by the university, and hope to have more knowledge, especially about data security issues and of the WLAN installation and use. It seems that ICT novice students, and especially women - regardless what their level of ICT skills is - tend to rely on social support. This echoes the findings of Hynes and Rommes (2005).

It is known that the pedagogical use of ICTs requires careful planning, and best practices are often found through long-term development and repeated implementations (Jonassen et al., 2005; Nicol \& McLeod, 2005). At present however, pedagogical planning seems to start from planning a single course's activities and interactions, whereas we suggest that strategic and long-term planning should also consider the multi-level and complex domestication process that precedes actual courses and learning processes. A single training session during which tools are introduced cannot answer all the needs that students have regarding their personal learning tools. In practice, based on the four aspects of domestication revealed in our analysis, we suggest first of all that institutions provide sufficient social support that is available to students who need hands on assistance with their laptops. This can be arranged for example through a help desk system, or if there is an existing student tutor system, the tutors could be trained also to help with laptop problems.

Perhaps it could be considered to arrange a special starting course for students with laptops during which the ICT infrastructure at the university would be thoroughly presented to students. Also, students' previous experience of using laptops and networks should be taken into consideration. For example having software that is already familiar to students installed to laptop can lower the threshold of starting to 
use the new tool in learning. If students have to learn how to use all new software in addition to the subject that is under study, it may slow down the learning process remarkably. Being able to use tools that students themselves prefer, make the tool feel closer to them. Finally, we suggest that students should be carefully guided to use any mobile services that are provided by the institution. This way students could better maintain active also when they are off campus. Also network based help desk could help students dealing with laptop problems while they occur. This could be arranged for example by using Skype or similar communication software.

No study is without limitations. It needs to be carefully noted that the dividing line between ICT novices and ICT experienced students achieved through $\mathrm{K}$-means cluster analysis, only gave the two groups from which the interviewees were selected. Having students distributed into two groups does not imply that all students in one group are identical in their ICT skills. There are differences among the skills of ICT novices, even though they all represent the same group. The students close to the limiting value on both sides of the dividing line are actually quite close to each other in terms of their skills, but there is some significant fact that determines to which group a student belongs to. The sampling of the interviewees may also have been affected by the fact that the survey's response rate was quite small.

However, we managed to get interviewees from all five faculties, both male and female students, and students of versatile age groups. The data was collected some five years ago, but the analysis and results can be safely reflected at present. Same kind of interview data could be collected from the student population that enrolled the university in fall 2009. Individual experiences are of course always unique, but both ICT novices and experts among the student population can yet be found. Even though we discussed the differences in domestication process between genders, we do not aim to generalise from these results but instead wanted to reach rich, in depth findings from a focused qualitative study.

To conclude, the results of this study highlight the importance of structuring and systematising the way in which laptop computer initiatives are organised in universities. It cannot be taken for granted that all enrolling students have good enough ICT skills to manage putting their laptops into use. Students are on different skill levels and have unique personal preferences, thus they need different kinds of support at the beginning. Successful domestication is nevertheless a critical phase of studies on a wireless campus, since students consider having a personal laptop computer in their use throughout their studies as a significant asset. It enables storing their whole studying history in one place in a form that, for example, essays, designs, reports and studying diaries can be accessed, read, edited and carried wherever. This article adds to the growing number of studies using domestication as an analytical and theoretical framework - it builds on the Silverstone foundations of media technology domestication and brings the concept of domestication into an under-researched area.

\section{Acknowledgments}

The study reported here is part of the MobIT Project (Developing Mobile NetworkBased Teaching, Studying and Learning Processes), funded by the Finnish Ministry of Education for the years 2007 to 2009. 


\section{References}

Aldenderfer, M. S. \& Blashfield, R. K. (1987). Cluster analysis. A Sage University paper No. 44. Beverly Hills: Sage Publications.

Barak, M., Lipson, A. \& Lerman, S. (2006). Wireless laptops as means for promoting active learning in large lecture halls. Journal of Research on Technology in Education, 38(3), 245-263.

Clemmensen, T. (2004). Four approaches to user modelling - a qualitative research interview study of HCI professionals' practice. Interacting with Computers, 16(4), 799-829.

Cohen, L., Manion, L. \& Morrison, K. (2007). Research methods in education. New York: Routledge.

Corbin, J. (1997). Grounded theory in practice. Thousand Oaks, CA: Sage.

Cretchley, P. (2006). Does computer confidence relate to levels of achievement in ICT-enriched learning models? Education and Information Technologies, 12(1), 29-39.

Demb, A., Erickson, D. \& Hawkins-Wilding, S. (2004). The laptop alternative: Student reactions and strategic implications. Computers E Education, 43(4), 383-401.

Eriksson, M. J., Vuojärvi, H. \& Ruokamo, H. (2009). Laptop computers and wireless university campus networks: Is flexibility and effectiveness improved? Australasian Journal of Educational Technology, 25(3), 322-335. http:/ / www.ascilite.org.au/ajet/ajet25/eriksson.html

Gilbert, N. (1993). Researching social life. London: Sage.

Glaser B. \& Strauss, A. (1967). The discovery of grounded theory. Chicago: Aldine.

Habib, L. (2005). Domestication of learning environments in an institution of higher education. Presented at the 33rd Congress of the Nordic Educational Research Association, A Nordic Dimension in Education and Research, Myth or Reality?, 10-12 March, 2005, University of Oslo.

Haddon, L. (2006). The contribution of domestication research to in-home computing and media consumption. The Information Society, 22(4), 195-203.

Hynes, D. (2003). The role of computer courses in the domestication of the computers. Case study for the strategies of inclusion: Gender and the information society project (SIGIS).

Hynes, D. (2005). Digital multimedia use $\mathcal{E}$ consumption in the household setting. Unpublished doctoral dissertation, Dublin City University.

Hynes, D. \& Rommes, E. (2005). "Fitting the internet into our lives": IT courses for disadvantaged users. In T. Berker, M. Hartmann, Y. Punie \& K. Ward (Eds), Domestication of media and technologies (pp. 123-144). Maidenhead: Open University Press.

Hynes, D. (2009). [End] users as designers: The Internet in everyday life in Irish households. Anthropology in Action, 16(1), 18-29.

Hynes, D. \& Richardson, H (2009). What use is domestication theory to information systems research? In Y. Dwivedi, B. Lal, M. Williams, S. Schneberger \& M. Wade (Eds), Handbook of research on contemporary theoretical models in information systems. IGI Global.

Jonassen, D. H., Lee, C. B., Yang, C.-C. \& Laffey, J. (2005). The collaboration principle in multimedia learning. In R. E. Mayer (Ed), The Cambridge handbook of multimedia learning (pp. 247-270). Cambridge: Cambridge University Press. 
Jones, C., Dirkinck-Holmfeld, L. \& Lindström, B. (2006). A relational, indirect, meso-level approach to CSCL design in the next decade. International Journal of Computer Supported Collaborative Learning, 1(1), 35-56. [verified 3 Apr 2010] http:/ / oro.open.ac.uk/15353/

Kvale, S. (1996). InterViews. An introduction to qualitative research interviewing. Thousand Oaks, CA: Sage.

Lehtonen, M., Ruokamo, H. \& Tella, S. (2004). Towards a multidisciplinary metamodel for network-based mobile education: The MOMENTS metamodel. In L. Cantoni \& C. McLoughlin (Eds), Proceedings of World Conference on Educational Multimedia, Hypermedia and Telecommunications 2004 (pp. 2020-2025). Chesapeake, VA: AACE.

Lie, M. \& Sørensen, K. H. (1996). Making technology our own. Oslo: Scandinavian University Press.

McInnerney, J. M. \& Roberts, T. S. (2004). Online learning: Social interaction and the creation of a sense of community. Educational Technology E Society, 7(3), 73-81. http: / / www.ifets.info/journals/7_3/8.pdf

Nicol, D. J. \& McLeod, I. A. (2005). Using a shared workspace and wireless laptops to improve collaborative project learning in an engineering class. Computers $\mathcal{E}$ Education, 44(4), 459-475.

Osika, E. R. \& Sharp, D. P. (2002). Minimum technical competencies for distance learning students. Journal of Research on Technology in Education, 34(3), 318-325.

Pierson, J. (2006). Domestication at work in small businesses In T. Berker, M. Hartmann, Y. Punie \& K. Ward (Eds), Domestication of media and technologies (pp. 205-226). Maidenhead: Open University Press.

Punie, Y. (2003). A social and technological view of ambient intelligence in everyday life: What bends the trend? Key Deliverable, The European Media and Technology in Everyday Life Network, 2000-2003, Institute for Prospective Technological Studies Directorate General Joint Research Centre European Commission [viewed 2 April 2005, verified 3 Apr 2010]. http:/ / www.lse.ac.uk/collections/EMTEL/reports/punie_2003_emtel.pdf

Ruokamo, H. \& Tella, S. (2005). An M+I+T++ research approach to network-based mobile education (NBME) and teaching-studying-learning processes: Towards a global metamodel. The IPSI BgD Transactions on Advanced Research: Multi-, Inter-, and Transdisciplinary Issues in Computer Science and Engineering, 1(2), 3-12.

Räisänen, H. (2007). Students' expectations of data security, mobility and computer-supported collaborative learning on a wireless campus. In H. Ruokamo, M. Kangas, M. Lehtonen \& K. Kumpulainen (Eds), Proceedings of the 2 nd international Network-Based Education Conference (pp. 217-226). University of Lapland publications in Education 17. Rovaniemi, Finland: University of Lapland Printing Centre.

Räisänen, H., Lehtonen, M., Ruokamo, H. \& Isomäki, H. (2005). Network-based mobile teaching and studying on a wireless campus. In P. Kommers \& G. Richards (Eds), Proceedings of World Conference on Educational Multimedia, Hypermedia and Telecommunications 2005 (pp. 599-604). Chesapeake, VA: AACE.

Rogers, E M. (1995). Diffusion of innovations. New York: The Free Press.

Sieber, J. (1992). Planning ethically responsible research. London: Sage Publications.

Silverstone, R., Morley, D., Dahlberg, A. \& Livingstone, A. (1989). Families, technologies and consumption: The household and information and communication technologies. Uxbridge, Middlesex: CRIT. 
Silverstone, R. \& Hirsch, E. (1994). Consuming technologies: Media and information in domestic spaces. London: Routledge.

Silverstone, R. (1994). Television and everyday life. London: Routledge.

Stewart, J. (2002). Encounters with the information society: Personal and social issues in the appropriation of new media products in everyday life: adoption, non-adoption, and the role of the informal economy and local experts. Unpublished doctoral dissertation, University of Edinburgh. [viewed 7 Oct 2006, verified 3 Apr 2010] http: / / homepages.ed.ac.uk/jkstew/thesis/

Strauss, A. \& Corbin, J. (1998). Basics of qualitative research: Techniques and procedures for developing grounded theory. London: Sage Publications.

Suddaby, R. (2006). From the editors: What grounded theory is not. Academy of Management Journal, 49(4), 633-642.

Vuojärvi, H., Lehtonen, M. \& Ruokamo, H. (2008). The added pedagogical value of using laptops in computer-supported collaborative learning on a wireless campus. Proceedings of World Conference on Educational Multimedia, Hypermedia and Telecommunications 2008 (pp. 2760-2768). Chesapeake, VA: AACE.

Hanna Vuojärvi

University of Lapland, Faculty of Education, Centre for Media Pedagogy

PO Box 122, FI-96101 Rovaniemi, Finland

Email: Hanna.Vuojarvi@ulapland.fi

Hannakaisa Isomäki

University of Jyväskylä, Information Technology Research Institute

PO Box 35, FI-40014 University of Jyväskylä, Finland

Email: Hannakaisa.Isomaki@titu.jyu.fi

Deirdre Hynes

Manchester Metropolitan University, Department of Information and

Communications, Geoffrey Manton Building

Rosamond Street West, Off Oxford Road, Manchester, M15 6LL, UK

Email: D.Hynes@mmu.ac.uk 